\title{
Direct and Indirect Protection with Pediatric Quadrivalent Live- Attenuated Influenza Vaccination in Europe Estimated by a Dynamic Transmission Model
}

\section{Laetitia Gerlier ${ }^{1}$, Judith Hackett ${ }^{2}$, Richard Lawson², Sofia Dos Santos Mendes ${ }^{3}$, Catherine Weil-Olivier ${ }^{4}$, Markus Schwehm ${ }^{5}$, Martin Eichner ${ }^{6,7}$}

${ }^{1}$ QuintilesIMS, Real-World Evidence Solutions, Zaventem, Belgium

${ }^{2}$ AstraZeneca, Gaithersburg, MD, USA

${ }^{3}$ AstraZeneca, Brussels, Belgium (Current affiliation: MSD, Brussels, Belgium)

${ }^{4}$ Department of Pediatrics, University Paris VII, Paris, France

${ }^{5}$ ExploSYS GmbH, Leinfelden-Echterdingen, Germany

${ }^{6}$ Institute for Clinical Epidemiology and Applied Biometry, University of Tübingen, Tübingen, Germany

${ }^{7}$ Epimos GmbH, Dusslingen, Germany

For correspondence: Laetitia.Gerlier@quintilesims.com

\begin{abstract}
Objectives: To estimate the public health impact of annual vaccination of children with a quadrivalent liveattenuated influenza vaccine (QLAIV) across Europe.

Methods: A deterministic, age-structured, dynamic model was used to simulate influenza transmission across 14 European countries, comparing current vaccination coverage using a quadrivalent inactivated vaccine (QIV) to a scenario whereby vaccination coverage was extended to $50 \%$ of 2-17 year-old children, using QLAIV. Differential equations described demographic changes, exposure to infectious individuals, recovery and immunity dynamics. For each country, the basic reproduction number $\left(\mathrm{R}_{0}\right)$ was calibrated to published influenza incidence statistics. Assumed vaccine efficacy for children was 80\% (QLAIV) and 59\% (QIV). Symptomatic cases cumulated over 10 years were calculated per 100000 person-years. One-way sensitivity analyses were conducted on QLAIV efficacy in 7-17 year-olds (59\% instead of $80 \%$ ), durations of natural ( \pm 3 years; base case: 6, 12 years for influenza A, B respectively) and QLAIV vaccine-induced immunity (100\% immunity loss after 1 season; base case: $30 \%)$, and $\mathrm{R}_{0}(+/-10 \%$ around all-year average value).
\end{abstract}

Results: Across countries, annual QLAIV vaccination additionally prevents 1366-3604 symptomatic cases per 100000 population (average $2495 / 100$ 000, ie, a reduction of 47.6\% of the cases which occur in the reference scenario with QIV vaccination only). Among children (2-17 years), QLAIV prevents 551-1555 cases per 100000 population (average $990 / 100$ 000, ie, 67.2\% of current cases). Among adults, QLAIV indirectly prevents 726-2047 cases per 100000 population (average $1466 / 100$ 000, ie, 40.0\% of current cases). The most impactful drivers of total protection were duration of natural immunity against influenza $A, R_{0}$ and QLAIV immunity duration and efficacy. In all evaluated scenarios, there was a large direct and even larger indirect protection compared with the reference scenario.

Conclusions: The model highlights direct and indirect protection benefits when vaccinating healthy children with QLAIV in Europe, across a range of demographic structures, contact patterns and vaccination coverage rates.

Keywords: seasonal influenza, pediatric vaccination, live-attenuated influenza vaccine, indirect protection, dynamic transmission model, Europe 


\section{INTRODUCTION}

Published in 2012, the World Health Organization (WHO)'s position paper on influenza vaccination indicates that children less than 5 years of age (and especially those aged less than 2 years) bear a high burden of influenza, and ought to be targeted for vaccination where resources are available. ${ }^{1}$ Children also play an important role in the transmission of influenza viruses in the community. ${ }^{2}$ Therefore, besides protecting them directly, pediatric influenza vaccination further aims at reducing the overall spread of the virus and, thus, at indirectly reducing the number of cases in the entire population, particularly in those at high risk of developing complications. In most European Union (EU) countries however, influenza vaccination policies target only individuals with high complication risk from 6 months of age, ie, with chronic disease/immune deficiency or aged $\geq 65$ years, representing about 180 million individuals (36\%) in the EU-27 population. ${ }^{3}$

Countries having implemented influenza vaccination programmes including healthy children now have data available that show the real-life benefits of such vaccination strategies. Indeed, reported studies document the indirect (herd) protection effect when vaccinating school-age children and the direct effect of routine pediatric vaccination programmes. ${ }^{4-7}$ In ddition to real-life studies, the potential added value of using mathematical models to assess and compare the impact of alternative vaccination strategies is appreciable. ${ }^{8-10}$ In our study, we used a dynamic transmission model (initially developed for Germany ${ }^{11,12}$ and previously adapted to France ${ }^{13}$ and Belgium ${ }^{14}$ ) to estimate the public health impact of pediatric influenza vaccination in different European countries.

\section{Aims and Objectives}

This study aims to estimate the public health impact of extending annual influenza vaccination from high-risk individuals to include healthy children aged 2-17 years, in 14 European countries, comprising Austria, Belgium, Finland, France, Germany, Greece, Italy, Luxembourg, The Netherlands, Poland, Portugal, Spain, Sweden, and the United Kingdom.

\section{METHODS}

\section{Study Design}

A deterministic, age-structured, dynamic transmission model was used to simulate the transmission of influenza in the population and to compare different vaccination strategies including direct and indirect protection effects. Demographic changes and transmission dynamics are described by a system of interacting differential equations. Technical details on the two-strain version of the simulation tool, previously used for Germany, were published elsewhere. ${ }^{11,12}$ The current simulation tool considers the concomitant and independent transmission of four influenza strains: $\mathrm{A}(\mathrm{H} 1 \mathrm{~N} 1), \mathrm{A}(\mathrm{H} 3 \mathrm{~N} 2)$, one B strain coming from the B/Victoria lineage, and one B strain coming from the B/Yamagata lineage. Model inputs are presented in Table 1 (values common to all countries) and Table 2 (country-specific values).

\section{Demographics and Contact Patterns}

The population was subdivided into 1 -year age cohorts and risk classes. Demographic data and population projections for each country were retrieved from EuroStat and from the national statistics institute of each country (Table 2). In line with the current recommendations in most EU countries, the "high-risk" group includes all individuals aged $>65$ years, and individuals from 6 months of age with immunodeficiency or any 
chronic cardiovascular, hepatic, renal, metabolic, neurological, or pulmonary comorbidity. ${ }^{15}$ In 2014 , it was estimated that $36 \%$ of the European population had at least one risk factor. ${ }^{3}$ For the model, we further assumed that the "high-risk" prevalence was 16.1\% until the age of 44 years and 32.1\% for the age group 45-64 years, plus, by definition, all persons aged $>65$ years (Table 1). ${ }^{3,15}$ "Non high-risk" individuals are referred to as "lowrisk". Contact patterns between individuals (i.e. average age-dependent numbers of contacts per person per day) were derived from the European Polymod study, using the matrix for physical and non-physical contacts. ${ }^{16}$ Contact data from a neighbouring country was used in absence of country-specific information (Table 2).

\section{Natural History of Influenza}

The all-year average of the seasonally fluctuating basic reproduction number $\mathrm{R}_{0}$ was calibrated to country-specific reported incidence data for laboratory-confirmed influenza. Calibration targets for influenza were derived from available incidence data of each country: either infection incidence, ${ }^{17,18}$ symptomatic cases, ${ }^{19-22}$ or physician visits, ${ }^{23-26}$ averaged over two or more seasons (Table 2). The basic reproduction number $\mathrm{R}_{0}$, representing the number of secondary infections produced by a single infected case, was assumed to vary over the year: it was $43 \%$ higher than the all-year average around Christmas and $43 \%$ lower in summer. ${ }^{27}$ The same value of $\mathrm{R}_{0}$ was used for each one of the four influenza strains which were assumed to be transmitted independently. To avoid virus transmission becoming extinct in the summer, the whole population was assumed to be further exposed to an external infection rate of 1 per 1000 susceptible person-years, which also fluctuated seasonally. The average duration of latency in the model was 1 day, followed by an average 5 -day period of contagiousness. ${ }^{28}$ Following infection, natural immunity was assumed to last on average for 6 years for influenza $\mathrm{A}$ and 12 years for influenza B. ${ }^{27}$ The proportion of individuals developing symptoms in case of infection was assumed to be $66.9 \%$ (Table 1). ${ }^{29}$

\section{Compared Vaccination Strategies}

After immunity patterns of the simulated population had been initialized during 20 years using the observed vaccination coverage and vaccine composition, allowing for transmission of the four influenza strains, two strategies were compared during ten influenza seasons, starting 2015-2016: (1) the reference strategy was the current coverage of high-risk individuals using quadrivalent inactivated influenza vaccine (QIV); (2) the evaluated strategy was an extension of current vaccination policy to 2-17 year-old healthy children using an intranasal, quadrivalent live-attenuated influenza vaccine (QLAIV) and increasing the coverage from the current level to a final coverage of $50 \%$ achieved in three annual steps. Children suffering from a severe form of asthma, representing about $11 \%$ of all high-risk children, ${ }^{30}$ are not eligible for a live-attenuated vaccine and, thus, continued to receive inactivated vaccine (QIV) in the model. Current vaccination coverage rates per age-risk group and country were derived from the most recent reports by the European Centre for Disease Prevention and Control (ECDC), ${ }^{31,32}$ multi-country surveys, ${ }^{33,34}$ and country-specific studies ${ }^{9,35-48}$ (Table 2). Vaccinations were assumed to be performed annually from October 1 to November 30. According to a study by the French sick fund, ${ }^{49}$ individuals vaccinated in a given year had a higher probability of being re-vaccinated the following year (odds ratio 30-60). A preferential re-vaccination factor was implemented in the simulations accordingly (Table 1).

\section{Vaccination Properties}

In the model, the vaccine efficacy was considered globally against all influenza strains. The vaccine efficacy against influenza infection in children aged 2-17 years, assessed in meta-analyses, was 59\% (95\% confidence interval $[41-71 \%])$ for the trivalent inactivated vaccine and $80 \%$ [68-87\%] for the trivalent live-attenuated 
vaccine. $^{50}$ The trivalent inactivated vaccine showed an efficacy of $60 \%$ [53-66\%] in healthy adults ${ }^{51}$ and $58 \%$ $\left[34-73 \%\right.$ in the population aged $>65$ years. ${ }^{52}$ The latter efficacy value was applied to all high-risk individuals using the inactivated vaccine. In the model, we assumed the efficacy of quadrivalent vaccines to be the same as that of the trivalent ones reported in the meta-analyses. ${ }^{53-55}$ The duration of vaccination-acquired immunity is known to wane quickly after vaccination with an inactivated vaccine; ${ }^{56,57}$ consequently, all QIV-acquired immunity was assumed to be lost after one influenza season. Immunity acquired by live-attenuated vaccination can last at least until the following season: according to an Asian study, 70\% of the vaccinees who were successfully immunised in the first year with a live-attenuated vaccine were also protected in the second year against matched strains without re-vaccination. ${ }^{58}$ Accordingly, we assumed that $30 \%$ of the immunity acquired by QLAIV vaccination was lost at the end of the first influenza season, whereas the remaining part was lost after the second season (Table 1).

\section{Model Outcomes}

In our model, the impact of the evaluated versus the current vaccination strategy was measured in terms of reduction of symptomatic influenza cases. The cases were cumulated over the 10 -year evaluation period and expressed as number of cases per 100000 person-years, which was either calculated separately for each country or cumulated over all 14 countries. The number of symptomatic influenza cases was estimated in the total population, and separately in the subgroup of children aged 2-17 years (targeted population, direct and indirect effects) and in adults aged $\geq 18$ years (indirect effect).

\section{Sensitivity and Scenario Analyses}

Vaccination coverage rates with QLAIV of $25 \%$ and $75 \%$ of the $2-17$ year age group were tested in two scenario analyses.

A tornado diagram was produced to show the impact of univariate variations of key parameters on the annual number of averted cases of symptomatic influenza. The included parameters were basic reproduction number $\mathrm{R}_{0}( \pm 10 \%$ around base case value), QLAIV efficacy of $59 \%$ in those aged $7-17$ years (ie, assuming the efficacy of QIV), duration of naturally acquired immunity ( \pm 3 years around base case), duration of QLAIV-induced immunity (assuming 100\% immunity loss after one season as with QIV), preferential re-vaccination factor (no increased probability or twice the base case value) and time horizon ( \pm 5 years).

\section{Correlation Analyses}

Correlations of the influenza incidence in each country with country-specific parameters were investigated, using Spearman's correlation coefficient. These parameters include demographic factors, contact patterns, current influenza vaccination coverage, and basic reproduction number $\mathrm{R}_{0}$. 


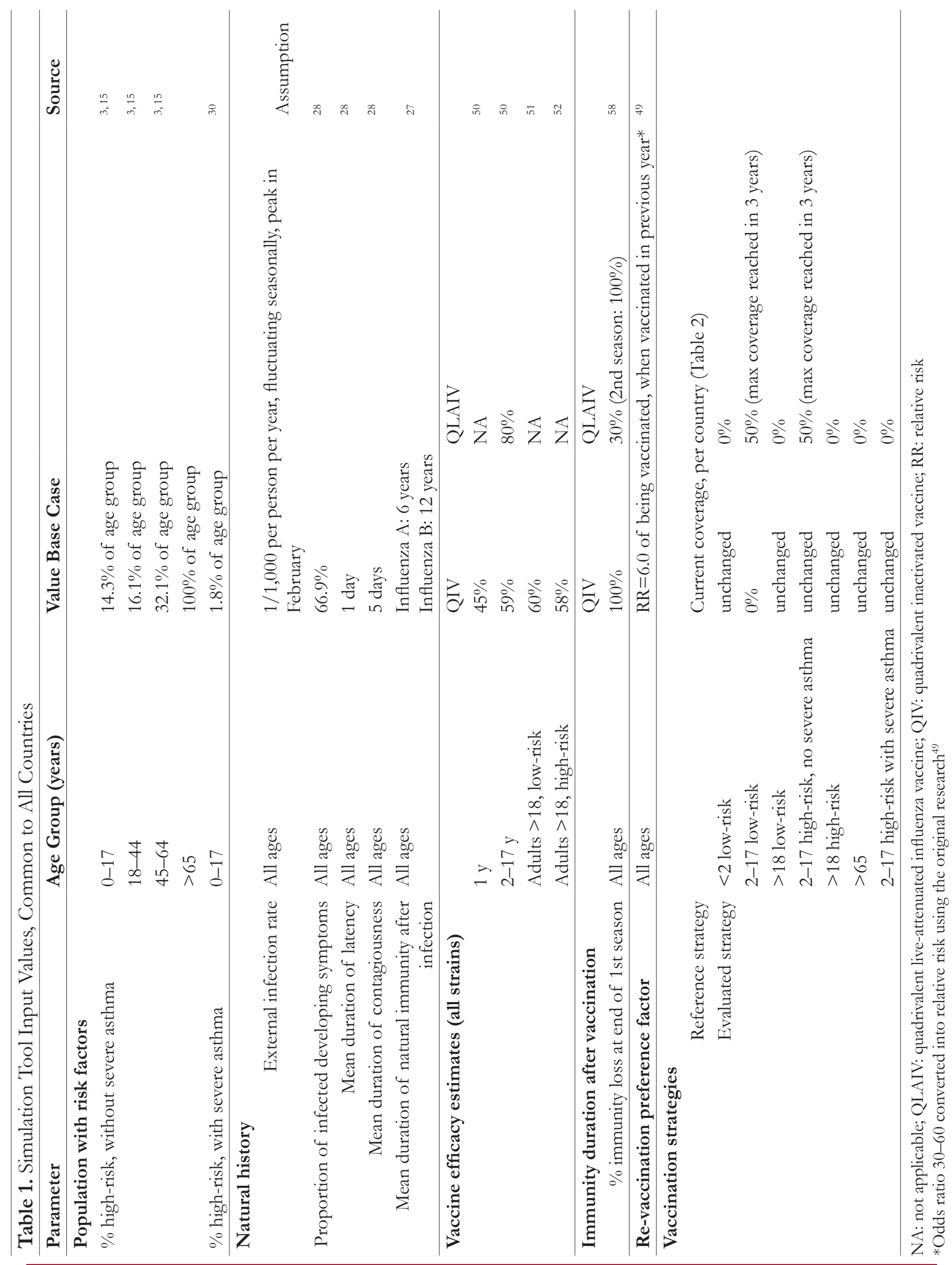




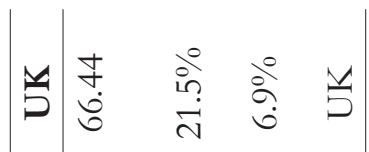

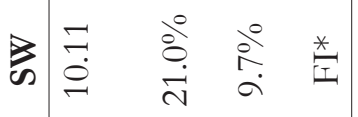

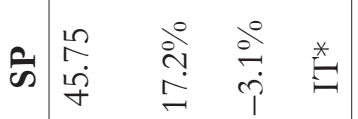

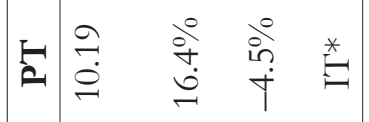

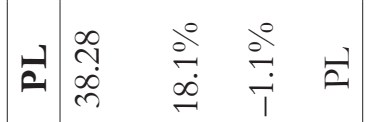

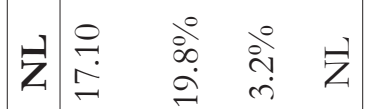

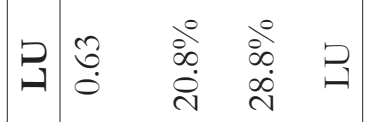

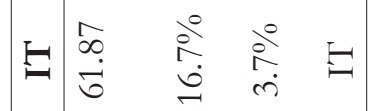

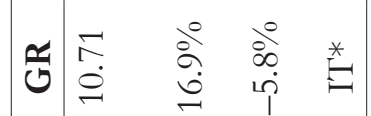

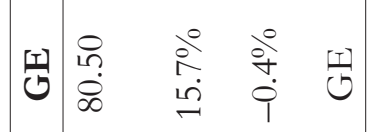

号

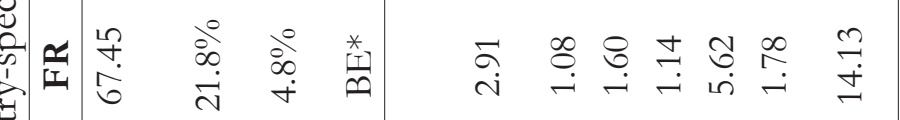

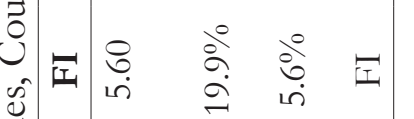

$\stackrel{\frac{0}{3}}{\frac{\pi}{2}}$

壱

مי

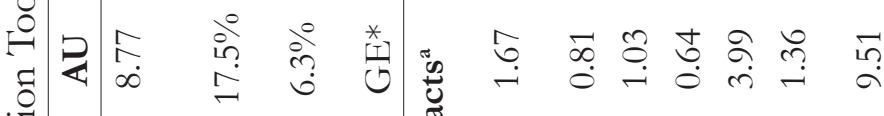

章

尝

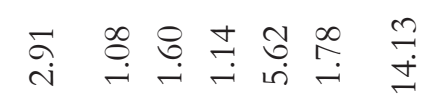

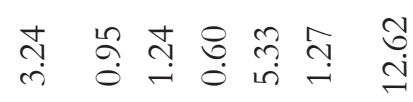

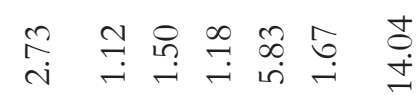

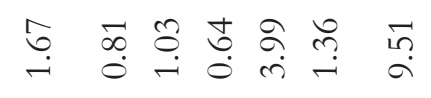

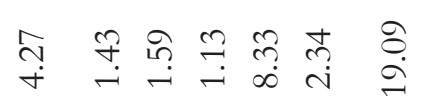

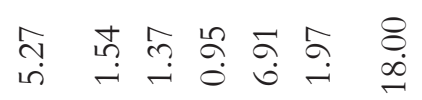

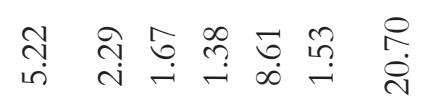

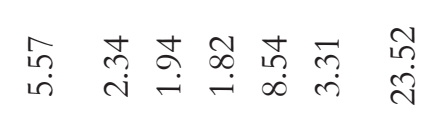

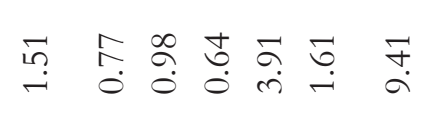

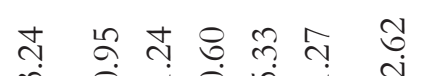

望敦 $\frac{9}{3}$ 造

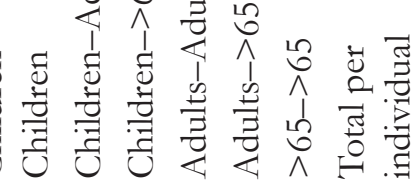

음

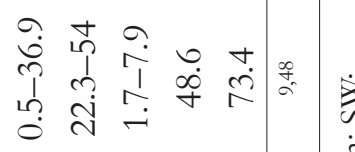

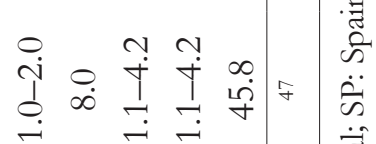

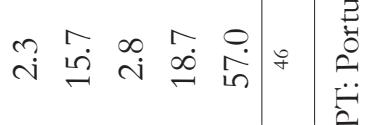

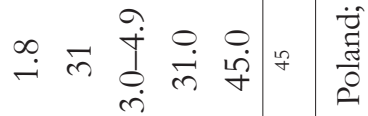

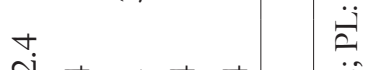

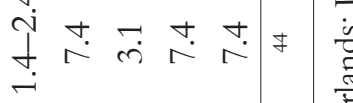

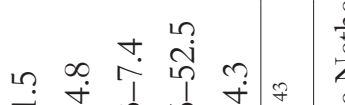

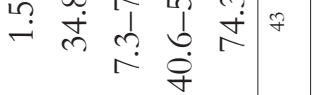

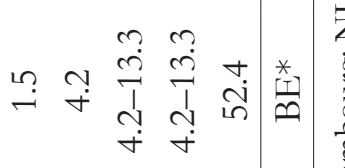

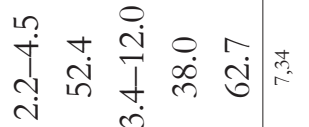

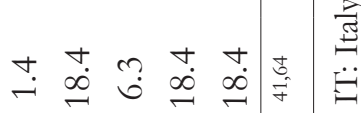

c

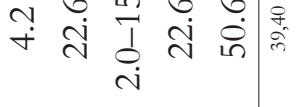

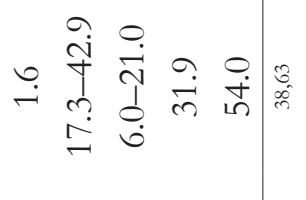

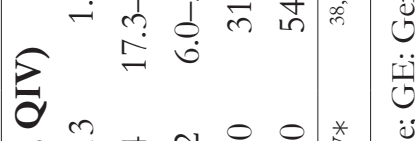

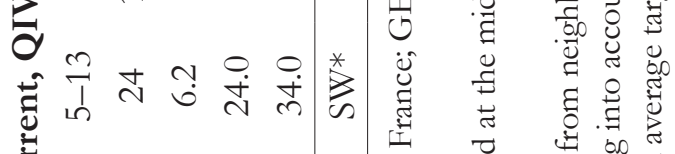

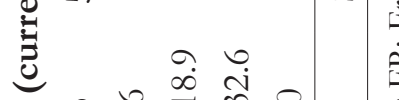

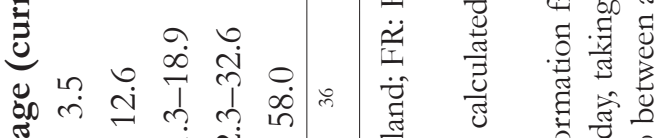$$
\text { हैं }
$$

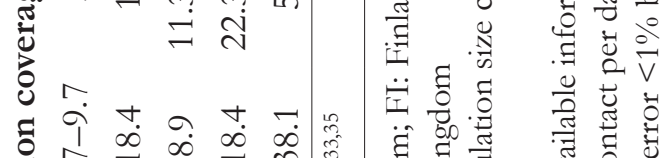

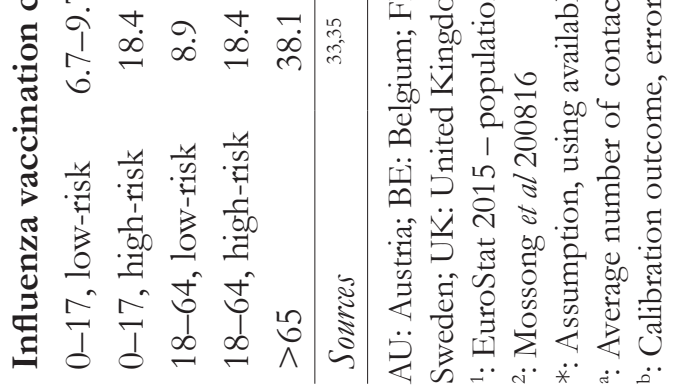




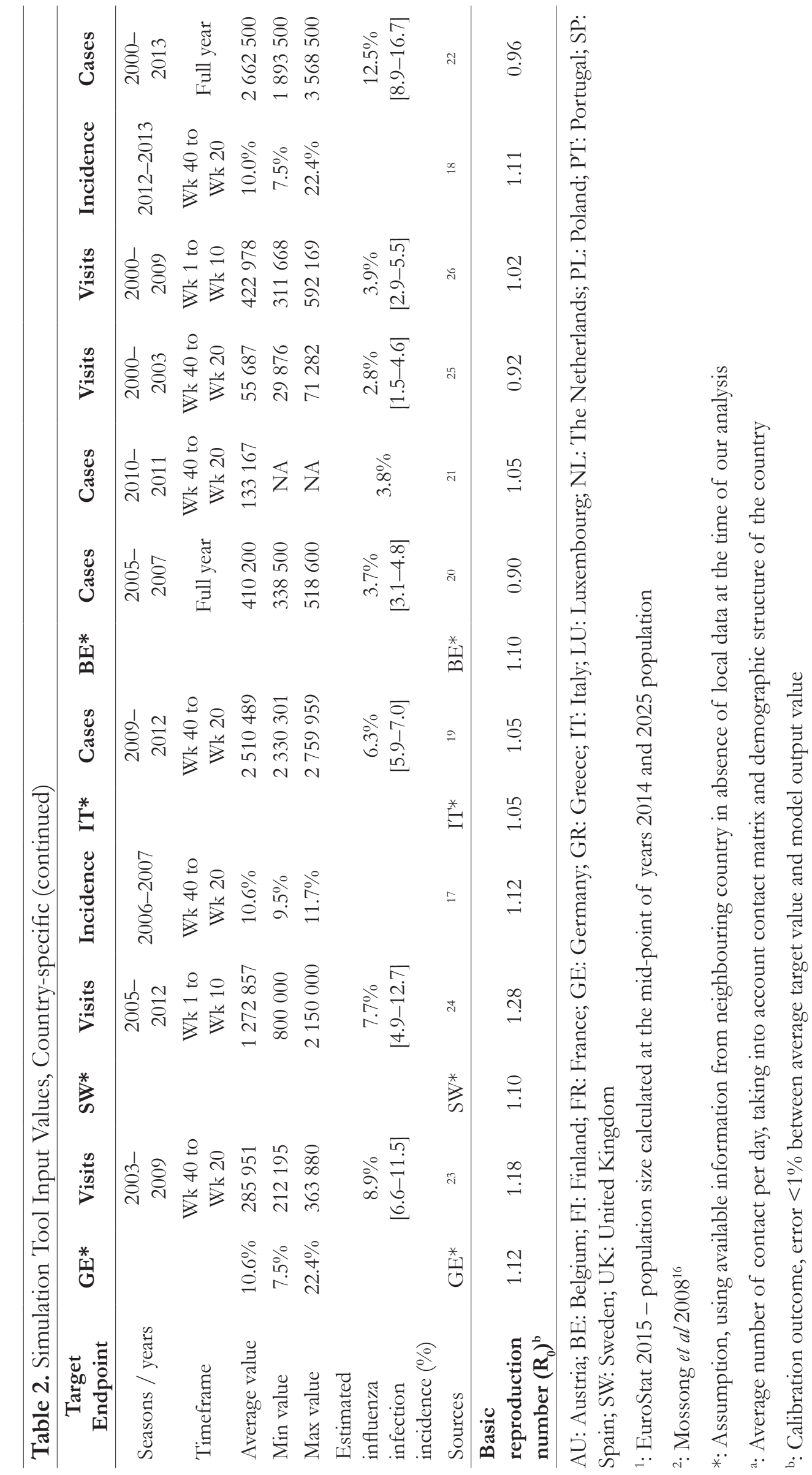




\section{RESULTS}

\section{Calibration}

Model calibrations reproduced country-specific incidence targets with error rates below 1\%, leading to values of the all-year average of $\mathrm{R}_{0}$ which ranged from 0.90 (implying an $\mathrm{R}_{0}$ peak value around Christmas of 1.29 ) to 1.28 (peak value 1.83) across countries (Table 2).

\section{Epidemiological Impact}

When considering QLAIV vaccination coverage of 50\% of children aged 2-17 years compared with the reference scenario, there were 2495 prevented symptomatic influenza cases per 100000 population-years in 14 European countries. This represents a reduction of $47.6 \%$ of the symptomatic cases which occur in the reference scenario, as the absolute number of cases dropped from 228.0 to 119.4 million over 10 seasons in the 14 countries included here (absolute numbers of cases per country are shown in Supplementary material S1). Across countries, the number of symptomatic influenza cases of any age prevented by pediatric QLAIV vaccination ranged from 1366 to 3604 cases per 100000 annually (lowest and highest values observed across 14 countries; see Table 3).

Among the targeted population of 2-17 year-old children, QLAIV vaccination prevented annually from 551 to 1555 symptomatic cases per 100000 population across countries and 990 cases per 100000 overall in the 14 countries that were included (Table 3). The number of pediatric cases cumulated over 10 years and 14 countries dropped from 64.1 to 21.0 million (ie, by $67.2 \%$, with 43.1 million prevented pediatric cases in the 14 countries combined).

As a result of indirect protection, the vaccination of 2-17 year-old children with QLAIV prevented annually a range of 726-2047 cases per 100000 population across countries (Table 3), including elderly aged $>65$ (pooled results for all 14 countries: 1466 prevented adult cases per 100000 annually, of which 157.6 were prevented elderly cases per 100 000). The number of adult cases of symptomatic influenza cumulated over 10 years and 14 countries dropped from 159.7 to 95.9 million (ie, by 40.0\%, with 63.8 million prevented adult cases in 14 countries).

The number of prevented cases in the non-target population (63.8 million) is $48 \%$ larger than the number of prevented cases in the target population (43.1 million). 


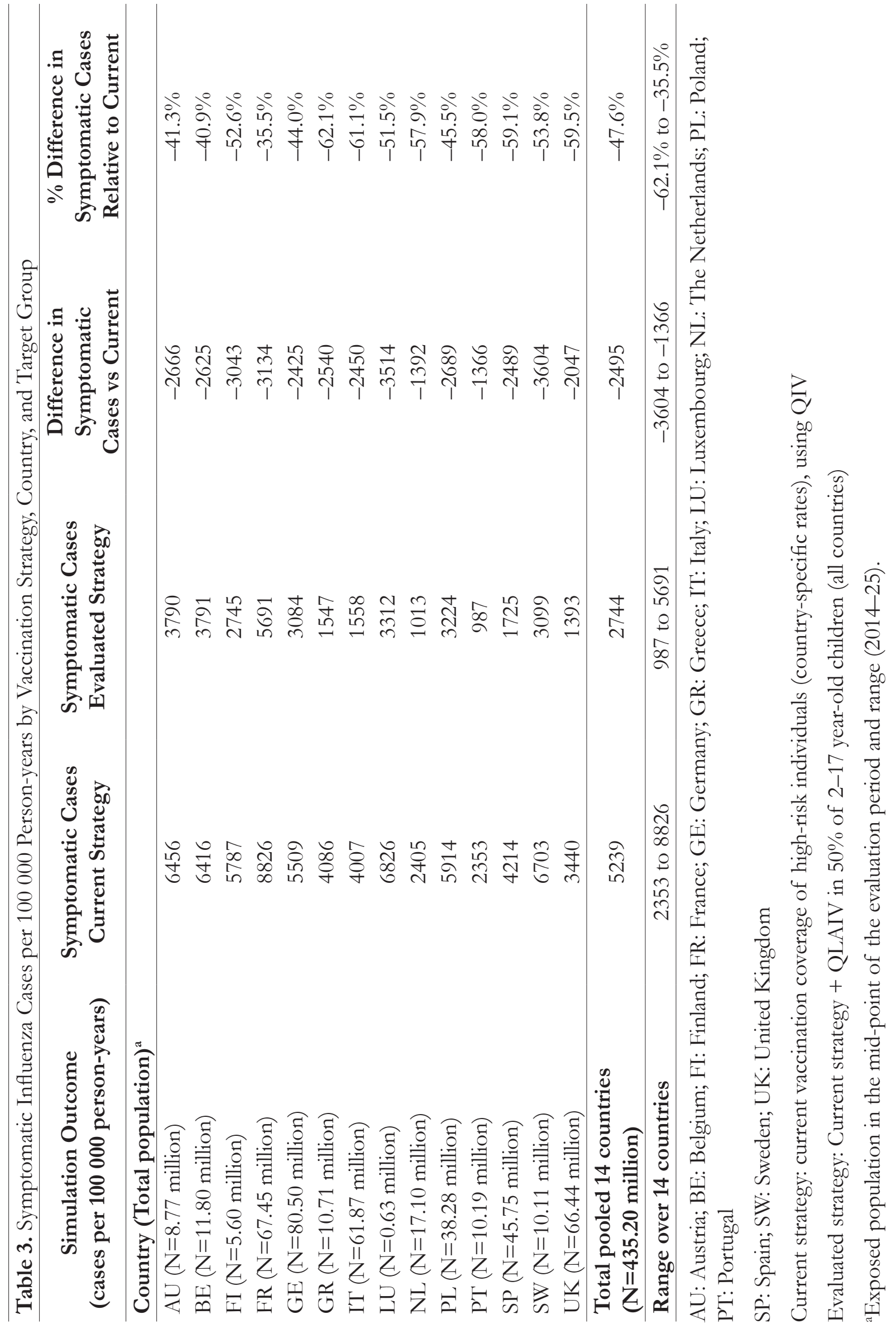




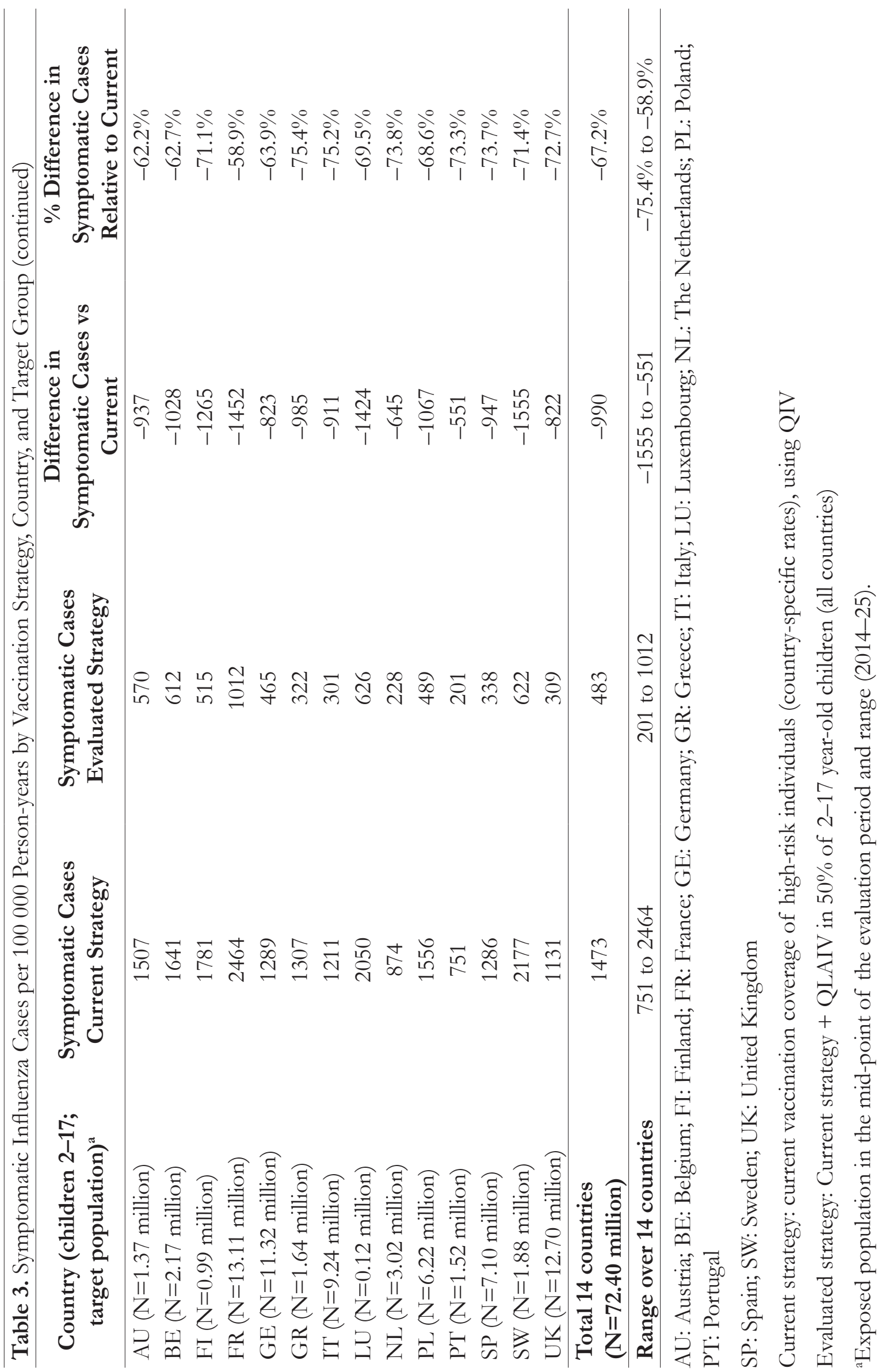




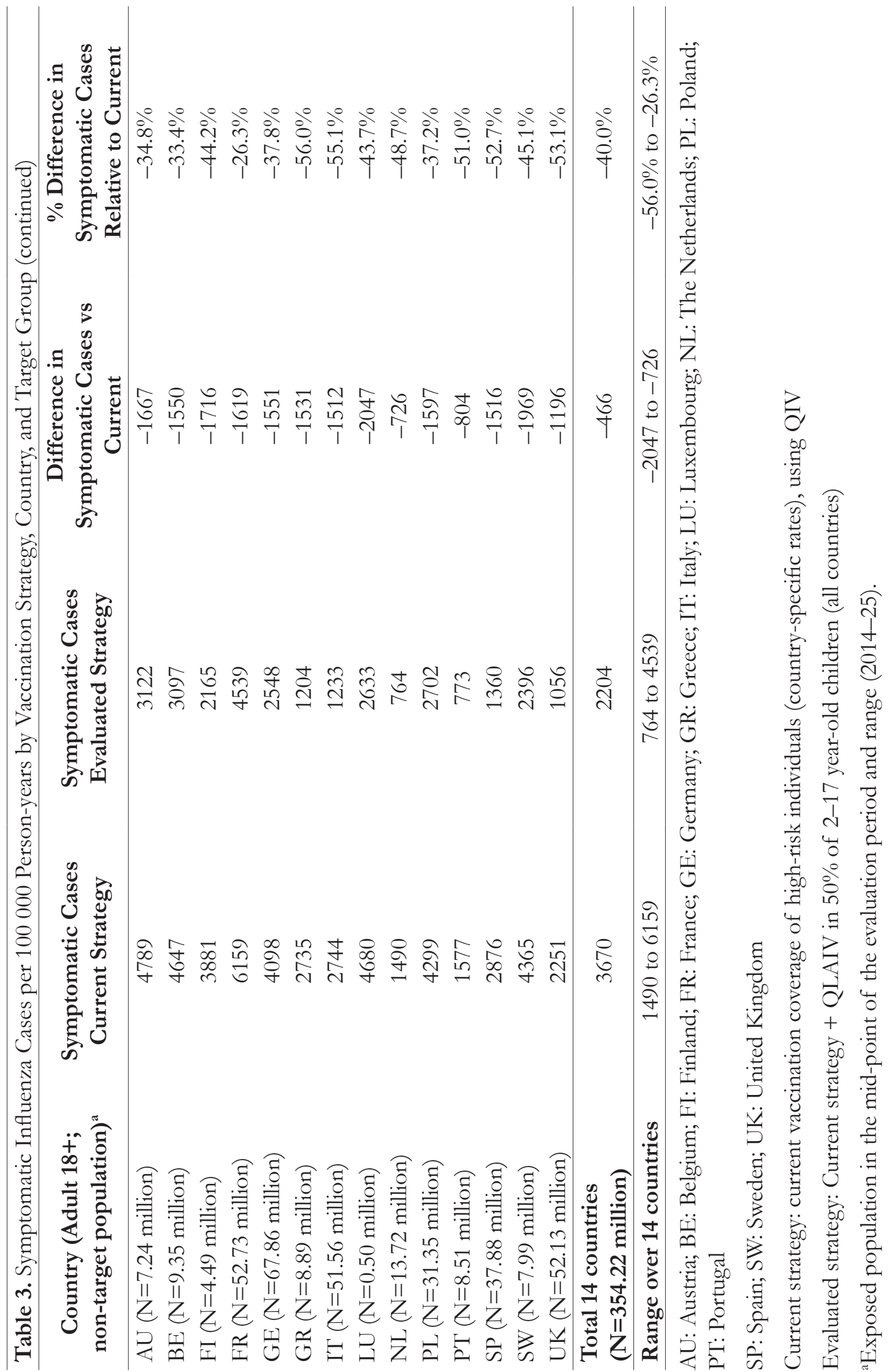




\section{Sensitivity Analyses}

Based on the univariate sensitivity analyses, the factors having the largest impact on the number of prevented influenza cases were the duration of natural immunity after influenza $A$ and the basic reproduction number $R_{0}$. A longer duration of naturally acquired immunity yielded fewer prevented cases (Figure 1a), both in the target (Figure $1 \mathrm{~b}$ ) and the non-target (Figure 1c) population. Using variations of $\pm 10 \%$ around the all-year average $\mathrm{R}_{0}$ in each country led to $20 \%$ more (3007 cases per 100000 person-years) and 27\% less (1824 cases per 100 000 person-years) averted symptomatic cases, respectively, compared to the base case outcome (2495 per 100 000 person-years). The number of annually prevented cases decreased to 2176 per 100000 (-41.5\% vs. current strategy; base case -47.6\%) when assuming a QLAIV efficacy of 59\% in 7-17 year-old children, and to 2127 per $100000(-40.5 \%)$ when assuming that all QLAIV-induced immunity is lost after one season (Figure 1a). A marked direct and indirect protection was found in each evaluated scenario compared to the current vaccinaton strategy using QIV (Figure 1).

The cumulated prevented symptomatic cases in the total population increased from 52.5 million after 5 years (2414 per 100000 person-years) to 155.7 million after 15 years (2385 per 100000 person-years).

Figure 1. Univariate Sensitivity Analysis, Impact on Prevented Symptomatic Cases (pooled 14 EU countries) 1a. Impact in Total Population

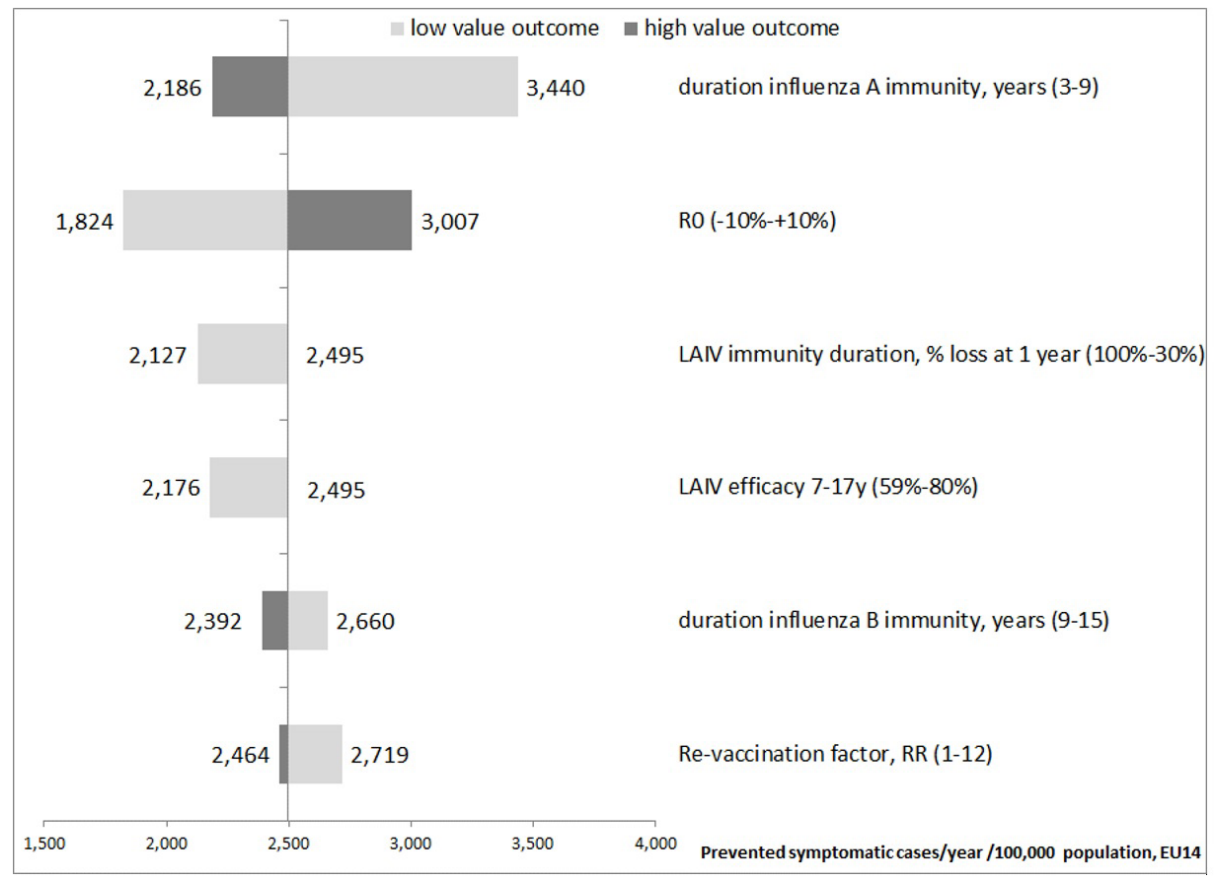

LAIV: live-attenuated influenza vaccine; $\mathrm{R}_{0}$ : basic reproduction number; RR: relative risk; VE: vaccine efficacy

Legend: The tornado charts in Figure 1 were obtained by changing the value of one parameter at a time and calculating the corresponding number of prevented symptomatic cases per 100000 person-years in the total population (Fig. 1a), in the target population (children aged 2-17 years; Fig. 1b) and in the adult population (aged $>18$ years; Fig. 1c). The results obtained with the lower (respectively higher) tested value are shown in light grey (respectively dark grey).

The vertical axes indicate the number of prevented cases in the base case analysis: 2495 cases of any age (Fig. 1a), 990 pediatric cases (Fig. 1b), and 1466 adult cases (Fig. 1c) per 100000 person-years.

The analysis highlights that the duration of naturally acquired immunity after influenza A infection (base case 6 years) and the basic reproduction number $\mathrm{R}_{0}$ have the highest impact on the results, both in the target (children) and the non-target (adult) populations. 
1b. Impact in Children Aged 2-17 years (target population)

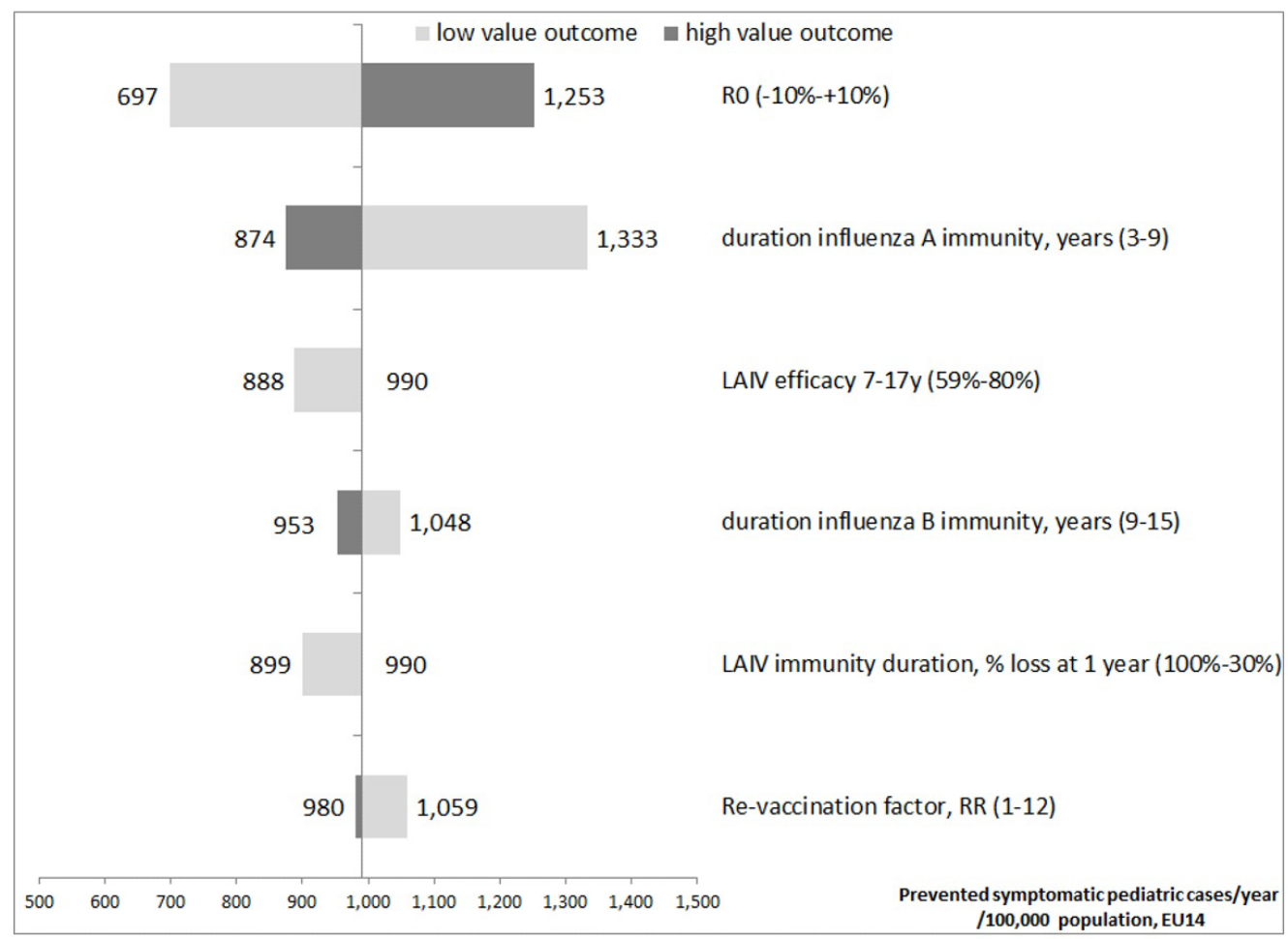

LAIV: live-attenuated influenza vaccine; $\mathrm{R}_{0}$ : basic reproduction number; RR: relative risk; VE: vaccine efficacy

1c. Impact in Adults $18+$ (non-target population)

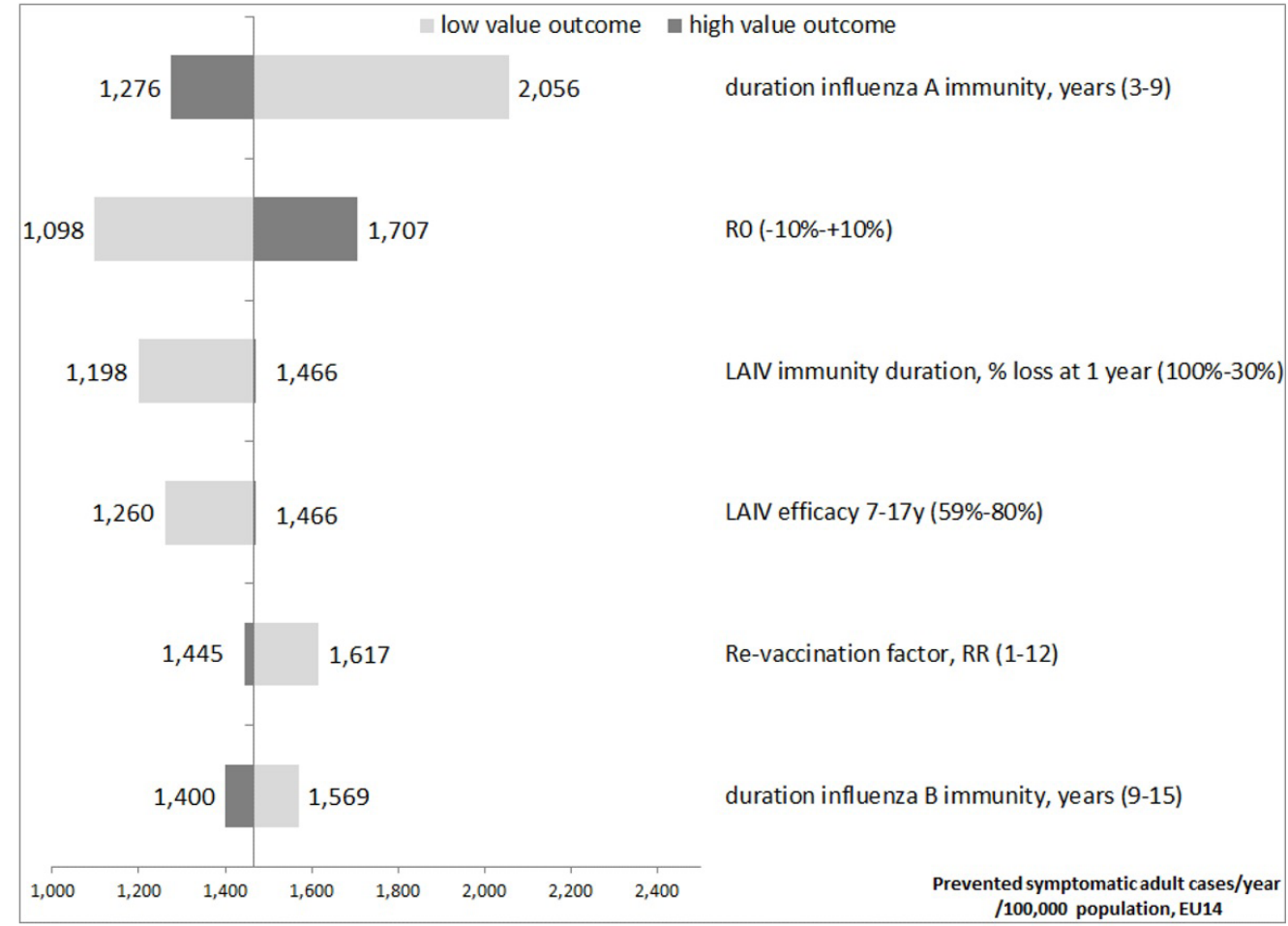

LAIV: live-attenuated influenza vaccine; $\mathrm{R}_{0}$ : basic reproduction number; $\mathrm{RR}$ : relative risk; VE: vaccine efficacy 


\section{Scenario Analyses}

When simulating a QLAIV coverage of 2-17 year-old children from 25\% to 75\%, the 10-year prevented cases ranged from 1532 to 3082 per 100000 person-years, the protection effect ranged from 647 to 1168 per 100 000 person-years in the targeted population, and from 861 to 1864 per 100000 person-years in the non-target population. With each tested coverage, the number of indirectly prevented cases exceeded the number of directly prevented cases in the target population (Figure 2).

Figure 2. Impact of QLAIV Coverage Rate on Symptomatic Case Reduction (pooled 14 EU countries)

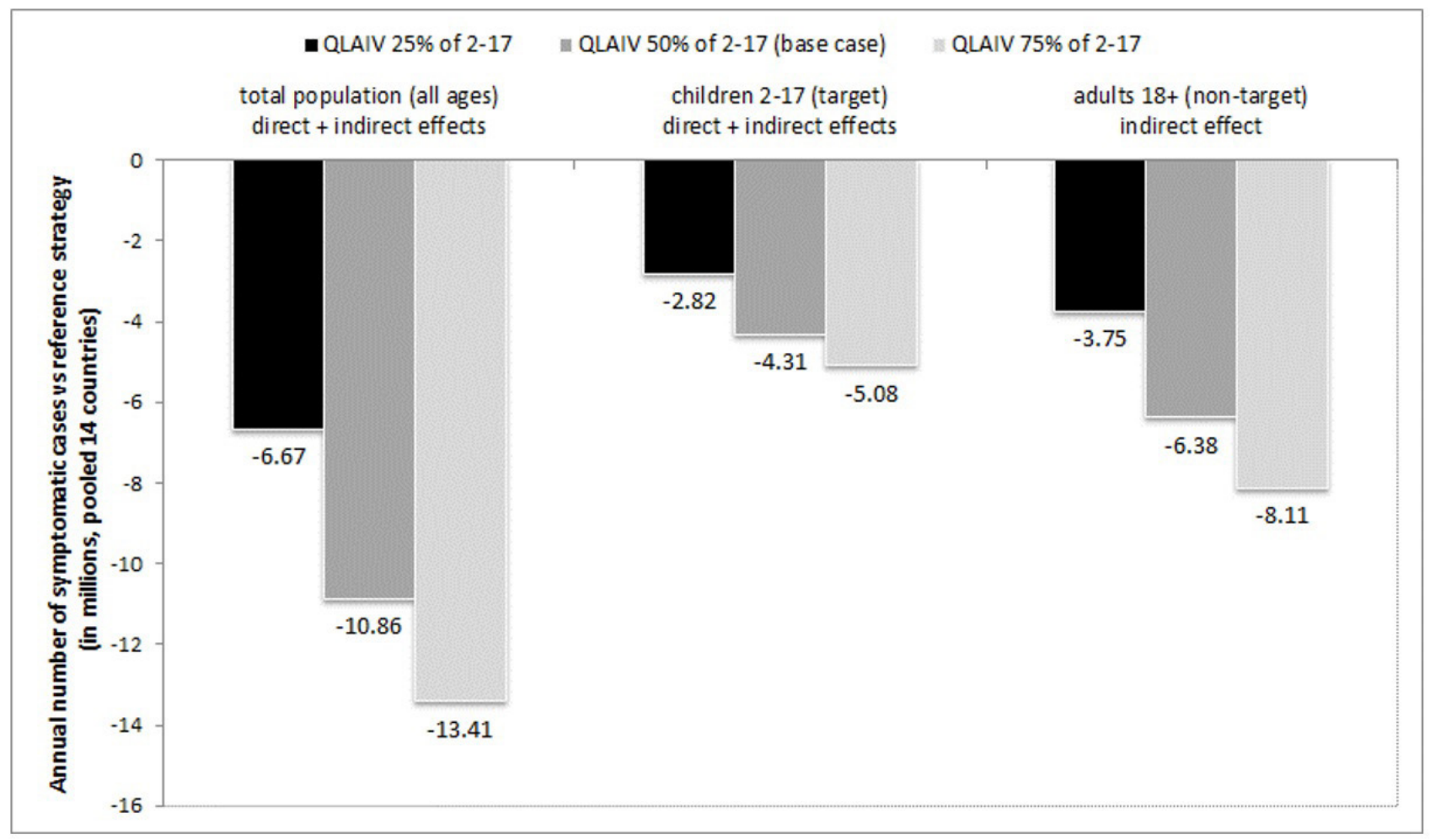

Legend: In general, the QLAIV vaccination started with the pre-existing vaccination coverage and was increased in three annual steps until the goal coverage of $25 \%, 50 \%$, or $75 \%$ was reached. Subpopulations which already exceeded the vaccination goal only switched to QLAIV without modifying their vaccination coverage:

Italy, 2-17 year high-risk (52.4\%)

The Netherlands, 2-17 year high-risk (34.8\%)

UK, 2 year low-risk 38.1\%, 3 year low-risk (40.7\%), 4 year low-risk (31.9\%), 2 year high-risk (53.7\%), 3 year high-risk (56.4\%), 4 year high-risk (52.3\%), 15-17 year high-risk (47.3\%).

\section{Correlation Analyses}

The country-specific parameters which most strongly correlated with the current number of symptomatic cases per 100000 person-years (as estimated by the model) were $\mathrm{R}_{0}$ (correlation coefficient 0.82 and $95 \%$ confidence interval [0.51;0.94]), the number of contacts between individuals aged $\geq 65$ years $(-0.62[-0.86$; -0.13]), the percentage of population growth from 2014 to 2025 (0.56 [0.05; 0.84]), the number of contacts between children and individuals aged $\geq 65$ years $(-0.54[-0.83 ;-0.01])$, and the current vaccination coverage rate of high-risk adults $(-0.53[-0.83 ; 0.00])$. Results of the correlation analysis are presented in Table 4. 
Table 4. Correlation Analysis of Country-specific Parameters with Number of Symptomatic Cases per 100000 Person-years

\begin{tabular}{lcc}
\hline \multicolumn{1}{c}{ Country-specific Parameter } & $\begin{array}{c}\text { Spearman Correlation } \\
\text { Coefficient }\end{array}$ & 95\% Confidence Interval \\
\hline Basic reproduction number R & 0.82 & $0.51 ; 0.94$ \\
Ratio Aged $>65$ / Aged 0-17 & -0.51 & $-0.82 ; 0.03$ \\
\% Population growth 2014-25 & 0.56 & $0.05 ; 0.84$ \\
\hline Number of contacts: & -0.54 & $-0.83 ;-0.01$ \\
Children (0-17) with Children & -0.48 & $-0.81 ; 0.07$ \\
Children with Adults (18-64) & -0.26 & $-0.69 ; 0.32$ \\
Children with $>65$ & -0.31 & $-0.72 ; 0.27$ \\
Adults with Adults & -0.20 & $-0.66 ; 0.37$ \\
Adults with $>65$ & -0.62 & $-0.86 ;-0.13$ \\
$>65$ with $>65$ & & $-0.83 ; 0.00$ \\
\hline QIV coverage: & -0.53 & $-0.69 ; 0.32$ \\
For high-risk adults (18-64) & -0.25 & \\
For $>65$ & &
\end{tabular}

Analysis based on the number of symptomatic cases in the reference scenario of 14 countries.

A positive correlation coefficient indicates that the number of symptomatic cases per 100000 person-years and the tested factor tends to vary in the same direction (eg, number of cases increases when $\mathrm{R}_{0}$ increases).

A negative correlation coefficient indicates that the number of symptomatic cases per 100000 person-years and the tested factor tends to vary in opposite directions (eg, number of cases increases when the QIV coverage of high-risk adults decreases).

A $95 \%$ confidence interval not including zero indicates that the correlation is statistically significant ( $\mathrm{p}$-value $<0.05)$.

\section{DISCUSSION}

Our results demonstrate large epidemiological benefits in Europe comprised of both direct and indirect elements if healthy children aged 2-17 years are vaccinated with QLAIV and a 50\% vaccine coverage rate is reached. Results were robust and conclusions remained unchanged across a range of univariate sensitivity and scenario analyses. The most influential parameters are the duration of naturally acquired immunity after influenza $A$ infection and the basic reproduction number $\mathrm{R}_{0}$.

The magnitude of our results is moderate compared to the highly positive results of UK modelling studies which reported that up to $84 \%$ of cases can be averted (as compared to the current policy over multiple seasons) in the total population when vaccinating $50 \%$ of the children with LAIV. ${ }^{8,9}$ This difference is partly due to an effect which can also be seen in our simulations: in the first years after introducing a new vaccination campaign, the annual incidence reaches a minimum before (a few years later) a new, slightly higher quasiequilibrium establishes. This effect (which has been termed "honeymoon period" ${ }^{59}$ ) is caused by a combination of natural immunity aquired in earlier years while transmission was still high, and the newly increased level of vaccination-derived immunity. Our approach of increasing the vaccination coverage over 3 years and evaluating a time period of 10 years, therefore, should come to somewhat more moderate results than a scenario in which the vaccination coverage may be abruptly increased with evaluation of benefit shortly thereafter. While dynamic transmission models are difficult to compare given the range of required assumptions and sophisticated programming techniques, the different published models to date do highlight a clinical benefit of pediatric LAIV vaccination. The countries' specificities, including contact patterns, demographic changes and influenza 
incidence targets, also account for different magnitudes of results as highlighted in the correlation analysis. These local parameters were found to strongly influence the success of vaccination. ${ }^{60}$ Our 14 countries were mainly selected based on their inclusion in the Polymod study as this study provided contact data suitable for modelization; ${ }^{16}$ further EU countries were added to increase the representativeness of our study at the European level. Our purpose was to present an overall EU picture of the QLAIV vaccination effect rather than a between-countries comparison. The calibration process ensures that local targets are reached by adjusting the basic reproduction number $\mathrm{R}_{0}$. However, given the independence of data sources used, the countries having the highest incidence targets are not necessarily those with, for example, the largest numbers of between-individual contacts. This explains why the modelled results can lead to counter-intuitive correlations with local factors (see Table 4) and why country differences can be expected.

Our study focused on symptomatic influenza cases, as the main purpose was to understand the magnitude of direct and indirect protection across a range of sensitivity analyses and country-specific features. Based on the prevented symptomatic cases, it is possible to extrapolate the modelled clinical benefit in each country to an impact in terms of medical resources used, which is relevant for decision makers. Assuming that 33\% of symptomatic cases lead to a primary care consultation and 1\% lead to an hospital admission ${ }^{61}$, our findings translate into 35.8 million prevented consultations and 1.09 million prevented hospitalisations cumulated over 10 years and 14 European countries. Ten QLAIV vaccinations are needed to prevent one influenza consultation, and 300 to prevent one hospitalisation. This finding is in line with real-life data published for season 2014-2015 in the UK where 16 QLAIV vaccinations were needed to prevent one consultation and 317 to prevent one hospitalisation, when vaccinating $56.8 \%$ of primary school age children. ${ }^{7}$ In recent seasons, however, lower QLAIV effectiveness against influenza A/H1N1pdm09 was observed ${ }^{62}$, which could not be included in our model at the time of our analyses. This trend is expected to impact the direct and indirect benefits described in this article, to an extent which remains to be evaluated. Comparison of modelled and real-life outcomes from the UK programme will be the topic of subsequent research using the same European dynamic transmission model.

As observed data are still scarce, modelling studies highlight a positive impact of a pediatric immunisation programme against influenza, across a range of demographic features, contact patterns, current vaccination coverage, and local influenza incidence. Our analyses therefore inform policy makers of the benefit of pediatric QLAIV vaccination in Europe, not only in the targeted population of vaccinated children but also in terms of indirect protection against influenza-related outcomes in the general population.

\section{FINANCIAL SUPPORT}

This study was funded by an unrestricted grant from AstraZeneca.

\section{CONFLICT OF INTEREST}

JH, RL, and SDSM are or were employees of AstraZeneca at the time of the study. LG is an employee of IMS Health which has received consulting fees from AstraZeneca. MS is an employee and shareholder of ExploSYS $\mathrm{GmbH}$, which has received payments from Epimos $\mathrm{GmbH}$, a contract research and consulting institute, which has received research support and consulting fees from AstraZeneca. ME is a partner and shareholder of the contract research and consulting institute Epimos $\mathrm{GmbH}$, which has received consulting fees and research support from AstraZeneca, Novartis, and GlaxoSmithKline. CWO has received grants for congresses and honoraria for conferences and meetings from AstraZeneca, GlaxoSmithKline, Novartis, Pfizer, Sanofi-Pasteur, and Sanofi-Pasteur MSD. 


\section{AUTHORSHIP}

ME conceptualised the study. ME carried out the simulations and interpreted the results. MS designed and developed the simulation tool and provided technical support. LG provided local data inputs, analysed the simulation results, and drafted the manuscript. CWO, JH, RL and SDSM provided expertise and guidance on data input and assumptions. All authors critically appraised, corrected and approved the manuscript before submission.

\section{REFERENCES}

${ }^{1}$ Vaccines against influenza WHO position paper - November 2012. Wkly Epidemiol Rec 2012;87:461-76.

${ }^{2}$ Neuzil KM, Hohlbein C, Zhu Y: Illness among schoolchildren during influenza season: effect on school absenteeism, parental absenteeism from work, and secondary illness in families. Arch Pediatr Adolesc Med 2002;156:986-91.

${ }^{3}$ Preaud E, Durand L, Macabeo B, et al: Annual public health and economic benefits of seasonal influenza vaccination: a European estimate. BMC Public Health 2014;14:813.

${ }^{4}$ Glezen WP, Gaglani MJ, Kozinetz CA, et al: Direct and indirect effectiveness of influenza vaccination delivered to children at school preceding an epidemic caused by 3 new influenza virus variants. $J$ Infect Dis 2010;202:1626-33.

${ }^{5}$ Kwong JC, Stukel TA, Lim J, et al: The effect of universal influenza immunization on mortality and health care use. PLoS Med 2008;5:e211.

${ }^{6}$ Loeb M, Russell ML, Moss L, et al: Effect of influenza vaccination of children on infection rates in Hutterite communities: a randomized trial. JAMA 2010;303:943-50.

${ }^{7}$ Pebody RG, Green HK, Andrews N, et al: Uptake and impact of vaccinating school age children against influenza during a season with circulation of drifted influenza A and B strains, England, 2014/15. Euro Surveill 2015;20:30029.

${ }^{8}$ Pitman RJ, White LJ, Sculpher M: Estimating the clinical impact of introducing paediatric influenza vaccination in England and Wales. Vaccine 2012;30:1208-24.

${ }^{9}$ Baguelin M, Flasche S, Camacho A, et al: Assessing optimal target populations for influenza vaccination programmes: an evidence synthesis and modelling study. PLoS Med 2013;10:e1001527.

${ }^{10}$ Ultsch B, Damm O, Perleth M, et al: Health economics in immunization decision-making - Results from a systematic literature research and a stakeholder symposium in Germany. Value Health 2015;18:A569.

${ }^{11}$ Rose MA, Damm O, Greiner W, et al: The epidemiological impact of childhood influenza vaccination using live-attenuated influenza vaccine (LAIV) in Germany: predictions of a simulation study. BMC Infect Dis 2014;14:40.

${ }^{12}$ Damm O, Eichner M, Rose MA, et al: Public health impact and cost-effectiveness of intranasal live attenuated influenza vaccination of children in Germany. Eur J Health Econ 2015;16:471-88.

${ }^{13}$ Gerlier L, Weil-Olivier C, Carrat F, et al: Public health and economic impact of vaccinating children with a quadrivalent live attenuated influenza vaccine in France using a dynamic transmission model. Value Health 2014;17:A674.

${ }^{14}$ Gerlier L, Lamotte M, Dos Santos Mendes S, et al: Estimates of the public health impact of a pediatric vaccination program using an intranasal tetravalent live-attenuated influenza vaccine in Belgium. Paediatr Drugs 2016;18:303-18. 
15 European Centre for Disease Control and Prevention. Guidance - Priority Risk Groups For Influenza Vaccination. http://ecdc.europa.eu/en/publications/Publications/0808_GUI_Priority_Risk_Groups_for_ Influenza_Vaccination.pdf. Accessed June 6, 2017.

${ }^{16}$ Mossong J, Hens N, Jit M, et al: Social contacts and mixing patterns relevant to the spread of infectious diseases. PLoS Med 2008;5:e74.

17 Williams CJ, Schweiger B, Diner G, et al: Seasonal influenza risk in hospital healthcare workers is more strongly associated with household than occupational exposures: Results from a prospective cohort study in Berlin, Germany, 2006/07. BMC Infect Dis 2010;10:8.

${ }^{18}$ Swedish Institute for Communicable Disease Control. Influenza in Sweden Season 2012-2013. https:/ /www. folkhalsomyndigheten.se/pagefiles/15027/influenza-in-sweden-2011-2012.pdf. Accessed March 29, 2016.

${ }^{19}$ Gasparini R, Bonanni P, Amicizia D, et al: Influenza epidemiology in Italy two years after the 2009-2010 pandemic: need to improve vaccination coverage. Hum Vacin Immunother 2013;9:561-7.

${ }^{20} \mathrm{McD}$ onald SA, Presanis AM, De Angelis D, et al: An evidence synthesis approach to estimating the incidence of seasonal influenza in the Netherlands. Influenza Other Respir Viruses 2014;8:33-41.

${ }^{21}$ Kovacs G, Kalo Z, Jahnz-Rozyk K, et al: Medical and economic burden of influenza in the elderly population in central and eastern European countries. Hum Vaccin Immunother 2014;10:428-40.

${ }^{22}$ Baguelin M, Camacho A, Flasche S, et al: Extending the elderly- and risk-group programme of vaccination against seasonal influenza in England and Wales: a cost-effectiveness study. BMC Med 2015;13:236.

${ }^{23}$ Hanquet G, Jonckheer P, Vlayen J, et al: Seasonal influenza vaccination: priority target groups - Part 1. Good Clinical Practice (GCP). KCE Reports 162C. https://kce.fgov.be/sites/default/files/page_documents/ kce_162c_seasonal_influenza_vaccination.pdf. Accessed June 6, 2017.

${ }^{24}$ Institut National de Veille Sanitaire (INVS). BEH - Bulletin épidémiologique hebdomadaire. http://invs. santepubliquefrance.fr//Publications-et-outils/BEH-Bulletin-epidemiologique-hebdomadaire. Accessed March 29, 2016.

${ }^{25}$ Nunes B, Viboud C, Machado A, et al: Excess mortality associated with influenza epidemics in Portugal, 1980 to 2004. PLoS One 2011;6:e20661.

${ }^{26}$ Larrauri Camara A, Jimenez-Jorge S, Mateo Ontanon S, et al: Epidemiology of the 2009 influenza pandemic in Spain. The Spanish influenza surveillance system. Enferm Infecc Microbiol Clin 2012;30 Suppl 4:2-9.

${ }^{27}$ Vynnycky E, Pitman R, Siddiqui R, et al: Estimating the impact of childhood influenza vaccination programmes in England and Wales. Vaccine 2008;26:5321-30.

${ }^{28}$ Carrat F, Vergu E, Ferguson NM, et al: Time lines of infection and disease in human influenza: a review of volunteer challenge studies. Am J Epidemiol 2008;167:775-85.

${ }^{29}$ Carrat F, Sahler C, Rogez S, et al: Influenza burden of illness: estimates from a national prospective survey of household contacts in France. Arch Intern Med 2002;162:1842-8.

${ }^{30}$ Weil-Olivier C, Lina B: Vaccination coverage with seasonal and pandemic influenza vaccines in children in France, 2009-2010 season. Vaccine 2011;29:7075-9.

${ }^{31}$ European Centre for Disease Control and Prevention: Implementation of the Council Recommendation on seasonal influenza vaccination (2009/1019/EU). https://ecdc.europa.eu/sites/portal/files/media/ en/publications/Publications/Implementation-seasonal-influenza-vaccination-Council-RecommendationJan-2014.pdf . Accessed July 18, 2017. 
32 Mereckiene J, Cotter S, Nicoll A, et al: Seasonal influenza immunisation in Europe. Overview of recommendations and vaccination coverage for three seasons: pre-pandemic (2008/09), pandemic (2009/10) and post-pandemic (2010/11). Euro Surveill 2014;19:20780.

${ }^{33}$ Blank PR, Schwenkglenks M, Szucs TD: Vaccination coverage rates in eleven European countries during two consecutive influenza seasons. J Infect 2009;58:446-58.

${ }^{34}$ Influenzanet. Influenzanet: a network of European citizens fighting against influenza. https://www. influenzanet.eu/en/. Accessed March 29, 2016.

${ }^{35}$ Kunze U, Bohm G, Groman E: Influenza vaccination in Austria from 1982 to 2011: a country resistant to influenza prevention and control. Vaccine 2013;31:5099-103.

${ }^{36}$ ISP/WIV: HISIA: Belgian Health Interview Survey - Interactive Analysis. https:/ hisia.wiv-isp.be/SitePages / Home.aspx. Accessed March 27, 2016.

${ }^{37}$ Tuppin P, Samson S, Weill A, et al: Seasonal influenza vaccination coverage in France during two influenza seasons (2007 and 2008) and during a context of pandemic influenza A(H1N1) in 2009. Vaccine 2011;29:46327.

${ }^{38}$ Groupe d'Expertise et d'Information sur la Grippe (GEIG): Le taux de couverture vaccinale en France. http://www.grippe-geig.com/couverture-vaccinale.html. Accessed June 15, 2017.

39 Schröder-Bernhardi D, Grunow SS, Bauman U, Zöllner Y: Schutzimpfungen gegen Influenza werden bei Kindern und Jugendlichen äußerst selten durchgeführt - Ergebnisse einer Datenbankanalyse. In: 9 Jahrestagung der Deutschen Gesellschaft für Epidemiologie. Ulm; 2014. https://dgepi.de/fileadmin/pdf/ tagungen_workshops/Abstractband_DGEpi_2014.pdf (page 176). Accessed July 18, 2017.

${ }^{40}$ Bodeker B, Remschmidt C, Schmich P, et al: Why are older adults and individuals with underlying chronic diseases in Germany not vaccinated against flu? A population-based study. BMC Public Health 2015;15:618.

${ }^{41}$ Mamma M, Spandidos DA: Economic evaluation of the vaccination program against seasonal and pandemic A/H1N1 influenza among customs officers in Greece. Health Policy 2013;109:71-7.

${ }^{42}$ Krippler S: Enquête de couverture vaccinale au Grand-Duché de Luxembourg 2012. 2014. http:/ /www.sante. public.lu/fr/publications/e/enquete-couverture-vaccinale-lux-2012/index.html. Accessed January 1, 2017.

43 Tacken M, Jansen B, Mulder J, et al: Monitoring vaccinatiegraad Nationaal Programma Grieppreventie 2013. Available from: http://nl.sitestat.com/rivm/rivm-nl/s?link.documenten_en_publicaties.algemeen_ actueel.uitgaven.preventie_ziekte_zorg.griepprik.monitoring_vaccinatiegraad_nationaal_programma_ grieppreventie_npg\&ns_type=pdf\&ns_url=http:/ / www.rivm.nl/dsresource?objectid=1ad08a11-e384-4df8a60e-76505fb6a8c0\&type $=$ org\&disposition=inline. Accessed January 6, 2017.

${ }^{44}$ Brydak LB, Wozniak Kosek A, Nitsch-Osuch A: Influenza vaccines and vaccinations in Poland - past, present and future. Med Sci Monit 2012;18:RA166-71.

${ }^{45}$ Nunes B, Sousa Uva M, Roquette R, et al: Vacinação antigripal da população portuguesa na época 20132014 - Estudo na amostra ECOS. http:/ / www.ulsm.min-saude.pt/ResourcesUser/Documentos/Vacinacao_ antigripal_da_populacao_portuguesa_na_epoca_2013_2014.pdf. Accessed July 6, 2017.

${ }^{46}$ Jimenez-Garcia R, Esteban-Vasallo MD, Rodriguez-Rieiro C, et al: Coverage and predictors of vaccination against 2012/13 seasonal influenza in Madrid, Spain: Analysis of population-based computerized immunization registries and clinical records. Hum Vaccin Immunother 2014;10:449-55.

${ }^{47}$ Public Health Agency of Sweden: Influenza in Sweden Season 2013-2014. https: / www.folkhalsomyndigheten. se/pagefiles/18481/Influenza-in-Sweden-2013-2014.pdf. Accessed January 6, 2017. 
${ }^{48}$ Public Health England: Seasonal influenza vaccine uptake amongst GP patients in England. https://www. gov.uk/government/statistics/seasonal-flu-vaccine-uptake-in-gp-patients-in-england-winter-season-2014to-2015. Accessed January 6, 2017.

${ }^{49}$ Tuppin P, Samson S, Weill A, et al: Influenza vaccination coverage in France in 2007-2008: Contribution of vaccination refund data from the general health insurance scheme. Med Mal Infect 2009;39:780-8.

${ }^{50}$ Jefferson T, Rivetti A, Di Pietrantonj C, et al: Vaccines for preventing influenza in healthy children. Cocbrane Database Syst Rev 2012:CD004879.

${ }^{51}$ Jefferson T, Di Pietrantonj C, Rivetti A, et al: Vaccines for preventing influenza in healthy adults. Cochrane Database Syst Rev 2014:CD001269.

${ }^{52}$ Jefferson T, Di Pietrantonj C, Al-Ansary LA, et al: Vaccines for preventing influenza in the elderly. Cocbrane Database Syst Rev 2010:CD004876.

${ }^{53}$ Block SL, Yi T, Sheldon E, et al: A randomized, double-blind noninferiority study of quadrivalent live attenuated influenza vaccine in adults. Vaccine 2011;29:9391-7.

${ }^{54}$ Block SL, Falloon J, Hirschfield JA, et al: Immunogenicity and safety of a quadrivalent live attenuated influenza vaccine in children. Pediatr Infect Dis J 2012;31:745-51.

${ }^{55}$ Kieninger D, Sheldon E, Lin WY, et al: Immunogenicity, reactogenicity and safety of an inactivated quadrivalent influenza vaccine candidate versus inactivated trivalent influenza vaccine: a phase III, randomized trial in adults aged $>18$ years. BMC Infect Dis 2013;13:343.

${ }^{56}$ Ambrose CS, Wu X, Belshe RB: The efficacy of live attenuated and inactivated influenza vaccines in children as a function of time postvaccination. Pediatr Infect Dis J 2010;29:806-11.

${ }^{57}$ Belongia EA, Sundaram ME, McClure DL, et al: Waning vaccine protection against influenza A (H3N2) illness in children and older adults during a single season. Vaccine 2015;33:246-51.

${ }^{58}$ Tam JS, Capeding MR, Lum LC, et al: Efficacy and safety of a live attenuated, cold-adapted influenza vaccine, trivalent against culture-confirmed influenza in young children in Asia. Pediatr Infect Dis J 2007;26:619-28.

${ }^{59}$ Scherer A, McLean A: Mathematical models of vaccination. Br Med Bull 2002;62:187-199.

${ }^{60}$ Schmidt-Ott R, Schwehm M, Eichner M: Influence of social contact patterns and demographic factors on influenza simulation results. ${ }^{\text {BMC Infect Dis } 2016 ; 16: 646 .}$

61 Grippenet fr: Bilan de la saison 2014-2015. https://www.grippenet.fr/media/uploads/bilan_ saison_2014_2015.pdf. Accessed May 30, 2016.

${ }^{62}$ Flannery B, Chung J: Influenza vaccine effectiveness, including LAIV vs IIV in children and adolescents, US Flu VE Network, 2015-16. https://www.cdc.gov/vaccines/acip/meetings/downloads/slides-2016-06/ influenza-05-flannery.pdf. Accessed March 29, 2016. 